\title{
LC-MS/MS method for the simultaneous estimation of Cefepime and Tazobactam in dog plasma
}

\author{
Sukanta K. Naik, Vineet S. Zope, Rajesh P. Chavan, Ravindra D. Yeole, Kiran R. Patil*
}

Wockhardt Research Centre, D-4, MIDC, Chikalthana, Aurangabad-431006, MS, India

*Corresponding author: kpatil@wockhardt.com

\begin{abstract}
A high performance liquid chromatography (HPLC) method with tandem mass spectrometric detection (MS/MS) has been developed and validated for the simultaneous quantification of cefepime and tazobactam in dog plasma. The method was developed on amide column with isocratic elution. The developed method is simple and economic in terms of sample preparation. The method is specific, sensitive, accurate, precise and robust. The method was successfully applied for pre-clinical pharmacokinetic studies in dogs. The Tmax was found to be $0.5 \mathrm{~h}$, the mean $\mathrm{Cmax}$ and $\mathrm{AUC}_{(0-12)}$ displayed dose proportionate response.
\end{abstract}

Keywords: Cefepime, Tazobactam, Liquid chromatography, Mass spectrometry, Bioanalysis

\section{Introduction}

Cefepime is chemically ([6R,7R,Z]-7-[2-(2aminothiazol-4-yl)-2acetamido]-3-[1-methyl (methoxyimino) methyl)-8-oxo-5-thia-1-aza-bicyclo[4.2.0] ene-2 carboxylate. Cefepime is a fourthgeneration cephalosporin antibiotic. Cefepime has an extended spectrum of activity against Grampositive and Gram-negative bacteria, with greater activity against both types of organism than thirdgeneration agents. Tazobactam is chemically (2S,3S,5R)-3-methyl-7-oxo-3-(1H-1,2,3-triazol-1ylmethyl)-4-thia-1 azabicyclo [3.2.0] heptane-2carboxylic acid 4,4-dioxide. Tazobactam is an active pharmaceutical ingredient that inhibits the action of bacterial beta-lactamases, especially those belonging to the SHV-1 and TEM groups. It is used as its sodium salt, tazobactam sodium. Tazobactam is in combination with the extended spectrum $\beta$-lactam antibiotic piperacillin in the drug piperacillin/tazobactam, one of the popular antibiotic treatment for nosocomial pneumonia caused by Pseudomonas aeruginosa. Tazobactam broadens the spectrum of piperacillin by making it effective against organisms that express $\beta$ lactamase and would normally degrade piperacillin (1).

Cefepime - tazobactam combination indicates as a parenteral therapy for the treatment of moderate to harsh infections due to susceptible beta-lactamase producing microbial organisms. Cefepime - tazobactam combination is mainly pointed if the cefepime treatment is not effective. Cefepime - combination is arranged for the treatment of basic skin and skin structure infections, urinary tract infections (UTI) and difficult intra-abdominal infections in adults as well as children. General use of $3^{\text {rd }}$ generation cephalosporins and piperacillin-tazobactam have led to an increase in strains with multiple extended-spectrum $\beta$-lactamases (ESBLs) and Class $C \beta$-lactamases that have upper minimum inhibitory concentrations (MIC) for piperacillintazobactam and high-stage resistance to $3^{\text {rd }}$ and $4^{\text {th }}$ generation cephalosporins. Under this situation, carbapenems are generally used as empiric remedy for the cure of Gram-negative infections. This has given increase to multiple mechanisms of carbapenem resistance in Enterobacteriaceae and $P$. aeruginosa leading to the use of compromised therapies - colistin and tigecycline. Cefepime and tazobactam have approximately 20 years record of medical use. Both the agents have every time confirmed satisfactory safety and effectiveness in various indications. Taking in to account that the combination safety report would remain comparable to the individual components, cefepime-tazobactam combination would give a considerably positive benefit: risk proportion for the treatment of UTI and other indications involving certain multidrug-resistant (MDR) Gram-negative pathogens, agreeable only to carbapenems, thereby minimizing the therapeuticbelief on carbapenems. Looking at the safety and combined effective advantage of these two agents, a high proportion cefepime-tazobactam 
combination is currently under clinical development. This combination is being developed to treat the complicated urinary-tract infection (cUTI) [including pyelonephritis] and hospital-acquired bacterial pneumonia (HABP) / ventilator-associated bacterial pneumonia (VABP).

A literature survey shown that several chromatographic methods are reported for the determination of cefepime alone or in combination with other drugs in formulation as well as in different biological matrices (2-17). Also several liquid chromatographic methods are reported for the determination of tazobactam and in combination with other drugs in formulation as well as in different biological matrices (18-29). Few methods are reported for simultaneous determination of cefepime and tazobactam in various dosage forms but none is reported in biological matrix (30-34). The objective of this study was to develop and validate a bio-analytical method for simultaneous determination of cefepime and tazobactam in beagle dog plasma. The developed method would be then applied for the pre-clinical study samples for the assessment of pharmacokinetics of these important drugs in dogs when administered by intravenous route in various ratios.

\section{Material and methods}

\section{Chemicals and standards}

Cefepime for injection and tazobactam sodium were obtained from Aurobindo Pharma Limited, India. Commercially available Cefotaxime sodium injection (Alkem Laboratories, India) was used. The chemical structures for these compounds are shown in Figure 1. All the solvents and reagents used were of either HPLC or LC-MS grade. Acetonitrile (HPLC gradient grade, Rankem), ammonium formate (LC-MS grade, Fluka), formic acid (LCMS grade, Fluka) were used. Ultra pure water was obtained through Purelab classic (US Filters). Drug free heparinized dog plasma was obtained from healthy beagle dogs.

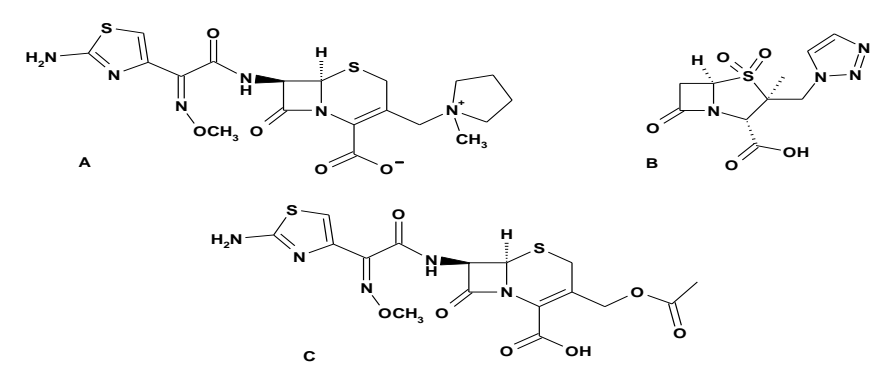

Figure 1. Chemical structures of Cefepime (A), Tazobactam (B) and Cefotaxime (C)

\section{Instrument and conditions}

High performance liquid chromatograph (Agilent 1100 series, Agilent Technologies) coupled with triple quadrupole mass spectrometer (API 3000, AB Sciex) was used for conducting bio-analysis. Agilent 1100 series HPLC consisted low pressure quaternary pump, degasser, thermostated auto-injector and thermostated column compartment. API 3000 mass spectrometer consisting of turbo-ion spray source interface was used for MS/MS analysis in positive ion mode.

The LC column used was Unisol Amide, $100 \mathrm{x}$ $4.6 \mathrm{~mm}, 3$ micron (Agela Technologies). The buffer solution was $25 \mathrm{mM}$ ammonium formate in water $\mathrm{pH}$ adjusted to 3.2 with formic acid. A mixture of buffer and acetonitrile $(25: 75 \mathrm{v} / \mathrm{v})$ was used as mobile phase. The flow rate was set at 1 $\mathrm{mL} / \mathrm{min}$. Column oven and auto-injector was set at $30^{\circ} \mathrm{C}$ and $10^{\circ} \mathrm{C}$ respectively. Injection volume was $3 \mu \mathrm{L}$ and run time 4.5 minutes.

\section{Standard and sample preparation}

Standard solution preparation for calibration
standards

Aqueous solutions containing cefepime and tazobactam were prepared in the range of 10 to $2000 \mu \mathrm{g} / \mathrm{mL}$ and were stored at $-70^{\circ} \mathrm{C}$. These solutions were diluted with drug-free plasma to yield calibration standards containing cefepime and tazobactam in the range of 0.5 to $100 \mu \mathrm{g} / \mathrm{mL}$.

\section{Internal standard (is) solution preparation}

Aqueous solution of Cefotaxime was prepared at $5 \mu \mathrm{g} / \mathrm{mL}$ and stored at $-20^{\circ} \mathrm{C}$.

Quality control (QC) samples preparation 
Aqueous solutions containing cefepime and tazobactam were prepared at 25,250 and 1500 $\mu \mathrm{g} / \mathrm{mL}$ and were stored at $-70^{\circ} \mathrm{C}$. These solutions were diluted with drug-free plasma to yield samples containing cefepime and tazobactam at 1.25 (LQC), 12.5 (MQC) and 75 (HQC) $\mu \mathrm{g} / \mathrm{mL}$; these QC samples were stored at $-70^{\circ} \mathrm{C}$.

\section{Plasma bank preparation}

In a $1.5 \mathrm{~mL}$ centrifuge tube $475 \mu \mathrm{L}$ of heparinized blank plasma was mixed with $25 \mu \mathrm{L}$ of water. In another centrifuge tube $50 \mu \mathrm{L}$ of this mixture was mixed with $750 \mu \mathrm{L}$ of acetonitrile and $200 \mu \mathrm{L}$ of water. This mixture was vortexed for 30 seconds and centrifuged for $3 \mathrm{~min}$ at $4000 \mathrm{~g}$ to remove precipitated proteins. The supernatant was used for analysis.

\section{Plasma blank with IS preparation}

Identical to the above procedure except addition of $200 \mu \mathrm{L}$ of IS solution instead of water.

\section{Study sample preparation}

In a $1.5 \mathrm{~mL}$ centrifuge tube $50 \mu \mathrm{L}$ of dog plasma was mixed with $750 \mu \mathrm{L}$ of acetonitrile and $200 \mu \mathrm{L}$ of IS solution. This mixture was vortexed for 30 seconds and centrifuged for $3 \mathrm{~min}$ at $4000 \mathrm{~g}$ to remove precipitated proteins. The supernatant was used for analysis.

\section{Method validation}

The method was validated as per the FDA and EMA guidelines on the subject to demonstrate the suitability of the method for intended purpose (3536). The validation was assessed for selectivity, matrix effect, sensitivity (Lower limit of quantification, LLOQ), linearity, accuracy, precision, recovery, dilution effect, carry over and stability parameters. The stability studies included short term stability (bench top stability), postpreparative stability (auto-injector stability), freeze thaw stability and long term stability.

\section{Selectivity}

The selectivity of the method was assessed by analyzing six blank plasma samples. The response of the interfering substances or background noise at the retention time of cefepime and tazobactam are acceptable if they are less than $20 \%$ of the response of the lowest concentration calibration standard. The response of the interfering substances or background noise at the retention time of internal standard are acceptable if it is less than $5 \%$ of the response of the internal standard in calibration standard.

\section{Matrix effect}

The matrix effect is investigated to ensure that precision, selectivity and sensitivity are not compromised by the matrix. Matrix effect was determined by analysing set of six LQC's and HQC's prepared in six different blank matrices. \% Accuracy and \% CV was determined for both QC's.

\section{Linearity, Precision and Accuracy}

Linearity was tested by determining response of ten non-zero standards in the concentration range of 0.5 to $100 \mu \mathrm{g} / \mathrm{mL}$. The acceptance limit of accuracy for each of the back calculated concentrations is $\pm 15 \%$ of the respective nominal concentration except at LLOQ, where it must be within $\pm 20 \%$ of the nominal concentration.

Precision and accuracy was evaluated by analyzing QC samples against freshly prepared calibration standards. Intra-day and inter-day precision and accuracy was determined by analyzing three sets of QC samples, two sets on single day and a set on another day. Accuracy of at least $67 \%$ QC samples must be within $\pm 15 \%$ of the respective nominal value except at LLOQ, where it must be within $\pm 20 \%$ of the nominal concentration. The accuracy of the $50 \%$ of the QC's injected at each level must be within $\pm 15 \%$ of the respective nominal concentration except at LLOQ, where it must be within $\pm 20 \%$ of the nominal concentration. The precision (\% CV) determined at each QC level must be $\leq 15 \%$, except for LLOQ where it must be $\leq 20 \%$. 
The recovery of cefepime and tazobactam was evaluated by preparing set of six samples at each QC concentrations in blank matrix and another set in water. The peak area of analytes and IS from both sets were compared to calculate recovery.

\section{Stability}

Stability of cefepime and tazobactam in dog plasma was assessed at three freeze-thaw cycles ($70^{\circ} \mathrm{C}$ to ambient temperature). Long term stability was evaluated by storing frozen plasma samples containing both analytes at $-70^{\circ} \mathrm{C}$ for 4 weeks. Bench-top stability was assessed for $4 \mathrm{~h}$ at room temperature. Post preparative stability was assessed at $10^{\circ} \mathrm{C}$ for $20 \mathrm{~h}$. All the stability was evaluated using six replicates of the LQC and HQC. The analytes are considered to be stable in the matrix if the accuracy is within $\pm 15 \%$ of the nominal concentration and $\% \mathrm{CV} \leq 1 \overline{5 \%}$.

\section{PK application}

The validated method was applied to determine the drug plasma concentrations from pre-clinical pharmaco-kinetics studies conducted in healthy male adult beagle dogs. The animals were administered the cefepime - tazobactam mixture at dose of 30 and $60 \mathrm{mg} / \mathrm{kg}$ each through $0.5 \mathrm{~h}$ infusion. Blood was collected in heparin containing tubes at prior to dosing $(-0.25 \mathrm{~h})$ and at $0.5,1.0,1.5,2.0,2.5,3.0,4.0,5.0,6.0,8.0,10.0$ and $12 \mathrm{~h}$ post administration. The blood samples were stored on ice bath until centrifugation to obtain plasma. Blood samples were centrifuged at $4000 \mathrm{~g}$ for $10 \mathrm{~min}$ to separate plasma. The plasma aliquots were stored at $-70^{\circ} \mathrm{C}$ until analysis in polypropylene tubes.

\section{Method development}

Mass spectrometry parameters of cefepime, tazobactam and IS were optimized by continuously injecting $10 \mu \mathrm{g} / \mathrm{mL}$ solution in to the turboionspray source using syringe pump. The declustering potential, focusing potential and entrance potential were optimized to achieve maximum response of the parent ion of both analytes and IS. Collision energy was adjusted to achieve maximum response of at least one daughter ion for each compound. The optimized MS parameters are presented in Table 1. The daughter ion of cefepime at $\mathrm{m} / \mathrm{z} 396.1$ arises due to the loss of N-Methyl pyrrolidine; the daughter ion of cefotaxime (IS) at $\mathrm{m} / \mathrm{z} 324.4$ arises due to loss of 2-amino thiazole and methoxy group. In tazobactam fragment $\mathrm{m} / \mathrm{z}$ 168.1 represents 3-(1H-1,2,3-triazol-1-yl)-2methyl butanoic acid which is formed due to loss of (4R)-4-(dioxido- $\lambda^{6}$-sulfanyl)-azetidin-2-one.

Table 1. Mass Spectrometer Parameters.

\begin{tabular}{lccc}
\hline & Cefepime & Tazobactam & $\begin{array}{c}\text { Cefotaxime } \\
\text { (IS) }\end{array}$ \\
\hline $\begin{array}{l}\text { Ion spray voltage } \\
\text { (Volts) }\end{array}$ & 5000 & 5000 & 5000 \\
$\begin{array}{l}\text { Source temperature } \\
\left({ }^{\circ} \mathrm{C}\right)\end{array}$ & 500 & 500 & 500 \\
$\begin{array}{l}\text { MRM transition } \\
\text { (amu) }\end{array}$ & $481.3>$ & $301.2>$ & $456.3>324.4$ \\
$\begin{array}{l}\text { Declustering } \\
\text { potential (Volts) }\end{array}$ & 396.1 & 168.1 & 47 \\
$\begin{array}{l}\text { Focusing potential } \\
\text { (Volts) }\end{array}$ & 24 & 28 & 250 \\
$\begin{array}{l}\text { Entrance potential } \\
\text { (Volts) }\end{array}$ & 195 & 175 & 10 \\
$\begin{array}{l}\text { Collision energy } \\
\text { (Volts) }\end{array}$ & 12 & 10 & 23 \\
$\begin{array}{l}\text { Collision cell exit } \\
\text { potential (Volts) } \\
\text { Dwell time (msec) }\end{array}$ & 10 & 25 & 10 \\
& 300 & 300 & 300 \\
\hline
\end{tabular}

During chromatography development, columns of various stationary phases like C18, C8, amide and HILIC were attempted with different mobile phases containing varying proportions of buffer solution and organic solvents. The objective was to separate two analytes and IS peaks devoid of matrix effect. Protein precipitation technique was used as sample preparation procedure due to economic factor. This procedure leads to presence of higher proportion of organic phase in sample to be injected on LC. Amide stationary phase LC column with isocratic elution was found to best suitable for application providing sufficient retention of the analytes and no matrix effect. The mobile phase used was a mixture of $25 \mathrm{mM}$ ammonium formate in water $\mathrm{pH} 3.2$ with formic acid and acetonitrile $(25: 75 ; \mathrm{v} / \mathrm{v})$. The higher percentage of organic phase in mobile phase also helped to achieve required mass spectrometer sensitivity. The mobile phase was passed through column at $1 \mathrm{ml} / \mathrm{min}$, the HPLC column was maintained at $30^{\circ} \mathrm{C}$, the injection 
volume was $3 \mu \mathrm{L}$ and overall run time was 4.5 min. The samples were maintained at $10^{\circ} \mathrm{C}$ in auto-injector. Carryover effect was investigated by injecting blank plasma preparation after highest concentration calibration standard; the resultant chromatograms did not reveal any carryover effect. Chromatograms of blank matrix, blank matrix with IS and study sample are shown in Figure 2, 3 and 4.

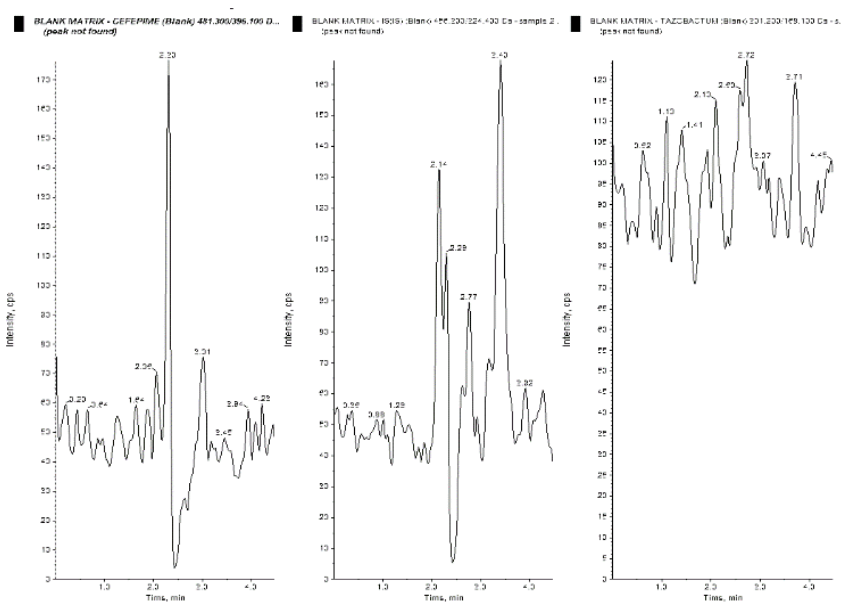

Figure 2. Representative chromatogram of blank matrix.

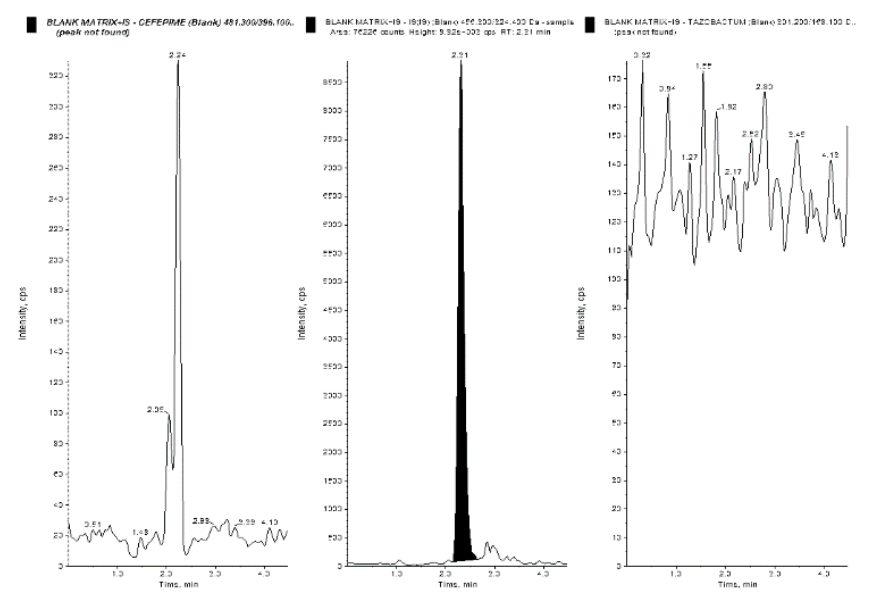

Figure 3. Representative chromatogram of blank matrix with IS.

Cefepime $\quad$ Cefotaxime (IS) Tazobactam

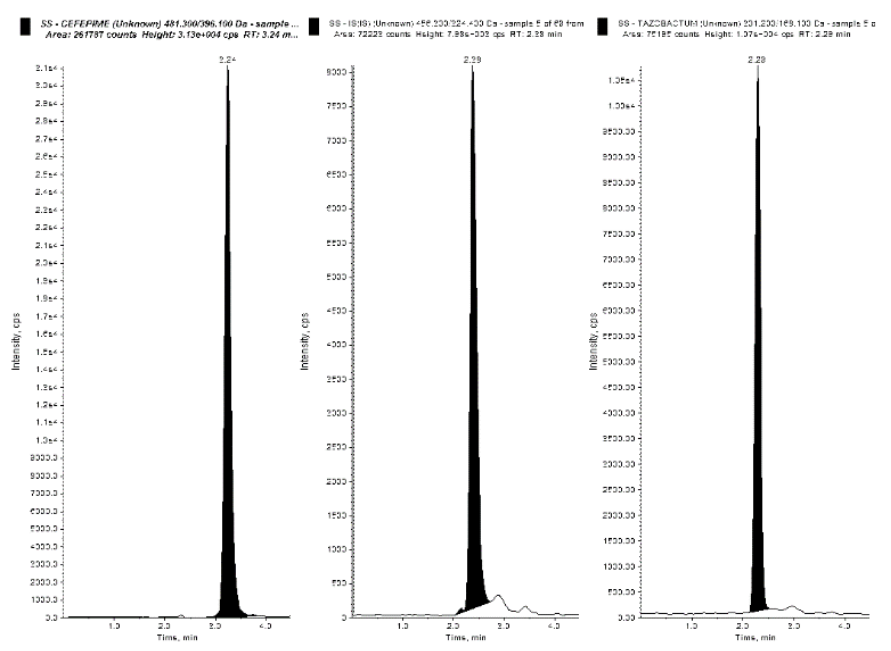

Figure 4. Representative chromatogram of study sample.

\section{Sample preparation}

Protein precipitation is a faster, straightforward and inexpensive method for extraction of analytes from biological matrices such as serum, plasma, feces, tissue fluids etc. This is preferred method when sample concentration enrichment is not required. In the present study the doses of both drugs are quite high and hence expected plasma levels were also high. Thus protein precipitation technique was found to be most suitable. Crashing out the proteins was achieved by adding acetonitrile.

\section{Results and discussion}

System suitability was carried out at the beginning of each run to verify the reproducibility of the method. The system suitability was verified by injecting 6 replicates of calibration standard $(25 \mu \mathrm{g} / \mathrm{mL})$ and determining the $\% \mathrm{CV}$ of the response for both analytes. The $\% \mathrm{CV}$ of the response for cefepime and tazobactam was found to be within the acceptable range $(\leq 10 \%)$ in all runs. None of the plasma obtained from 6 different animals showed presence of any interference at the retention time and mass transition of analytes and IS. A set of six LLOQ in drug free matrix was prepared and analyzed against freshly prepared calibration standards to determine \% accuracy and \% CV The detector response was found to be accurate and precise at $0.50 \mu \mathrm{g} / \mathrm{mL}$ of cefepime and 0.44 $\mu \mathrm{g} / \mathrm{mL}$ of tazobactam. The method was found to be sensitive enough to determine the plasma 
concentrations during elimination phase. The results are reported in Table 2.

Table 2. LLOQ data.

\begin{tabular}{lcccc}
\hline & $\begin{array}{c}\text { Nominal } \\
\text { Conc. } \\
(\boldsymbol{\mu g} / \mathbf{m L})\end{array}$ & $\begin{array}{c}\text { Found } \\
\text { Conc. } \\
\text { Mean } \\
(\boldsymbol{\mu g} / \mathbf{m L}) \\
(\mathbf{n = 6})\end{array}$ & $\begin{array}{c}\text { Accuracy } \\
(\mathbf{\%})\end{array}$ & $\begin{array}{c}\text { Precision } \\
(\boldsymbol{\%})\end{array}$ \\
\hline Cefepime & 0.50 & 0.46 & 92.00 & 6.15 \\
Tazobactam & 0.44 & 0.45 & 102.27 & 7.68 \\
\hline
\end{tabular}

The developed method did not show any ion suppression or enhancement effect as the concentration determined at two levels in six different plasma preparations was found to be accurate and precise. The results are reported in Table 3.

Table 3. Matrix effect.

\begin{tabular}{lcccc}
\hline & $\begin{array}{c}\text { Nominal } \\
\text { Conc. } \\
(\boldsymbol{\mu g} / \mathbf{m L})\end{array}$ & $\begin{array}{c}\text { Found Conc. } \\
\text { Mean } \\
(\boldsymbol{\mu g} / \mathbf{m L}) \\
(\mathbf{n = 6})\end{array}$ & $\begin{array}{c}\text { Accuracy } \\
(\boldsymbol{\%})\end{array}$ & $\begin{array}{c}\text { Precision } \\
(\boldsymbol{\%})\end{array}$ \\
\hline Cefepime & 1.25 & 1.21 & 96.80 & 2.81 \\
& 75.02 & 78.26 & 104.32 & 3.68 \\
Tazobactam & 1.11 & 1.11 & 100.00 & 4.08 \\
& 66.67 & 67.96 & 101.93 & 4.07 \\
\hline
\end{tabular}

Linearity, precision and accuracy (LPA) was carried out by preparing three batches of calibration standards, LLOQ, LQC, MQC and HQC; two batches were analyzed on single day and third batch on another. A batch contained plasma blank, plasma blank with IS, calibration standards and six replicates each of LLOQ, LQC, MQC and HQC samples.

Correlation coefficient, mean of found concentration, intraday and inter-day $\%$ accuracy and $\% \mathrm{CV}$ were determined. The results are presented in Table 4 and Table 5. Mean absolute recovery of cefepime, tazobactam determined at three concentrations was found to be consistent. Recovery was found to be $114.2 \pm 12.4 \%$ and $88.1 \pm 2.6 \%$ for cefepime and tazobactam respectively. Recovery for IS was found to be $87.5 \%$. Cefepime and tazobactam were found to be stable in dog plasma at all the studied conditions. The stability study results are presented in Table 6 and Table 7.

Table 4. Intra and Inter-day LPA data for cefepime.

\begin{tabular}{|c|c|c|c|c|c|c|}
\hline Analysis & $\begin{array}{c}\text { Calibration range } \\
(\mu \mathrm{g} / \mathrm{mL})\end{array}$ & Correlation coefficient & $\begin{array}{l}\text { QC conc. } \\
(\mu \mathrm{g} / \mathrm{mL})\end{array}$ & $\begin{array}{c}\text { Found conc. Mean } \pm \text { SD } \\
(\mu \mathrm{g} / \mathrm{mL}) \quad(\mathrm{n}=6)\end{array}$ & Precision \% & Accuracy \% \\
\hline \multirow{4}{*}{ Intra-day } & \multirow{4}{*}{$0.5-100.46$} & & 0.50 & $0.521 \pm 0.05$ & 9.46 & 104.00 \\
\hline & & Batch-1 0.9979 & 1.26 & $1.18 \pm 0.09$ & 7.61 & 93.65 \\
\hline & & Batch-2 0.9979 & 12.56 & $12.08 \pm 1.10$ & 9.10 & 96.18 \\
\hline & & & 75.34 & $79.28 \pm 8.05$ & 10.15 & 105.23 \\
\hline \multirow{4}{*}{ Inter-day } & \multirow{4}{*}{$0.5-100.46$} & \multirow{4}{*}{ Batch-3 0.9928} & 0.50 & $0.51 \pm 0.05$ & 9.72 & 102.00 \\
\hline & & & 1.26 & $1.20 \pm 0.14$ & 11.32 & 95.24 \\
\hline & & & 12.56 & $11.77 \pm 1.14$ & 9.66 & 93.71 \\
\hline & & & 75.34 & $72.75 \pm 8.14$ & 11.19 & 96.56 \\
\hline
\end{tabular}

Table 5. Intra and Inter-day LPA data for tazobactam.

\begin{tabular}{|c|c|c|c|c|c|c|}
\hline Analysis & $\begin{array}{c}\text { Calibration range } \\
(\mu \mathrm{g} / \mathrm{mL})\end{array}$ & $\begin{array}{c}\text { Correlation } \\
\text { coefficient }\end{array}$ & $\begin{array}{l}\text { QC conc. } \\
(\mu \mathrm{g} / \mathrm{m} L)\end{array}$ & $\begin{array}{c}\text { Found conc. Mean } \pm \text { SD } \\
(\mu \mathrm{g} / \mathrm{mL}) \quad(\mathrm{n}=6)\end{array}$ & Precision \% & Accuracy \% \\
\hline \multirow{5}{*}{ Intra-day } & \multirow{5}{*}{$0.44-88.16$} & Batch-1 & 0.44 & $0.47 \pm 0.05$ & 10.03 & 106.82 \\
\hline & & 0.9995 & 1.10 & $1.09 \pm 0.06$ & 5.59 & 99.09 \\
\hline & & Batch-2 & 11.02 & $10.61 \pm 0.49$ & 4.64 & 96.28 \\
\hline & & 0.9979 & 66.12 & $67.64 \pm 3.17$ & 4.68 & 102.30 \\
\hline & & \multirow{4}{*}{$\begin{array}{c}\text { Batch-3 } \\
0.9987\end{array}$} & 0.44 & $0.48 \pm 0.04$ & 8.75 & 109.09 \\
\hline \multirow{3}{*}{ Inter-day } & \multirow{3}{*}{$0.44-88.16$} & & 1.10 & $1.16 \pm 0.11$ & 9.18 & 105.45 \\
\hline & & & 11.02 & $10.99 \pm 0.76$ & 7.00 & 99.73 \\
\hline & & & 66.12 & $68.62 \pm 3.76$ & 5.48 & 103.78 \\
\hline
\end{tabular}


Table 6. Stability data of cefepime.

\begin{tabular}{lccccc}
\hline Study & QC Conc. $(\boldsymbol{\mu g} / \mathbf{m L})$ & $\begin{array}{c}\text { Found Conc. } \\
\text { Mean } \\
(\boldsymbol{\mu g} / \mathbf{m L})\end{array}$ & $\begin{array}{c}\text { Accuracy } \\
(\mathbf{\%})\end{array}$ & $\begin{array}{c}\text { Precision } \\
(\boldsymbol{\%})\end{array}$ & Stability period \\
\hline Bench top stability & 1.26 & 1.26 & 100.00 & 5.88 & $4 \mathrm{~h}$ \\
Post preparative stability & 75.34 & 74.75 & 99.22 & 5.95 & \\
& 1.26 & 1.35 & 107.14 & 3.14 & $20 \mathrm{~h}$ \\
Freeze thaw stability & 75.34 & 85.13 & 112.99 & 5.73 & \\
& 1.26 & 1.10 & 87.30 & 5.63 & 3 cycles \\
Long term stability & 75.34 & 69.04 & 91.64 & 8.50 & \\
& 1.26 & 1.32 & 104.76 & 9.97 & 4 weeks \\
\hline
\end{tabular}

Table 7. Stability data of tazobactam.

\begin{tabular}{lccccc}
\hline Study & QC Conc. $(\boldsymbol{\mu g} / \mathbf{m L})$ & $\begin{array}{c}\text { Found Conc. Mean } \\
(\boldsymbol{\mu g} / \mathbf{m L})\end{array}$ & $\begin{array}{c}\text { Accuracy } \\
(\mathbf{\%})\end{array}$ & $\begin{array}{c}\text { Precision } \\
(\boldsymbol{\%})\end{array}$ & Stability period \\
\hline Bench top stability & 1.10 & 1.10 & 100.00 & 4.88 & $4 \mathrm{~h}$ \\
Post preparative stability & 66.12 & 64.99 & 98.29 & 2.51 & \\
& 1.10 & 1.13 & 102.73 & 1.82 & $20 \mathrm{~h}$ \\
Freeze thaw stability & 66.12 & 66.14 & 100.03 & 4.24 & \\
& 1.10 & 1.12 & 101.82 & 5.50 & 3 cycles \\
Long term stability & 66.12 & 64.17 & 97.05 & 8.43 & \\
& 1.10 & 1.08 & 98.18 & 9.31 & 4 weeks \\
\hline
\end{tabular}

Impact of dilution was assessed by preparing six replicates of plasma samples at higher concentration than the linearity range. At the time of analysis these samples were diluted appropriately with drug free plasma to achieve 50 $\mu \mathrm{g} / \mathrm{mL}$ and then processed and analyzed. Results are reported in Table 8 and 9. The concentrations of the diluted samples were found to be accurate. The method was successfully developed, validated and applied for bioanalysis of plasma samples of pre-clinical pharmacokinetic studies in beagle dogs. The plasma concentration vs time profile is presented in Figure 5.

Table 8. Effect of dilution on cefepime.

\begin{tabular}{cccc}
\hline $\begin{array}{c}\text { Dilution } \\
\text { factor }\end{array}$ & $\begin{array}{c}\text { Conc. } \\
(\boldsymbol{\mu} \mathbf{g} / \mathbf{m L})\end{array}$ & $\begin{array}{c}\text { Found Conc. Mean } \\
(\boldsymbol{\mu g} / \mathbf{m L})\end{array}$ & $\begin{array}{c}\text { Accuracy } \\
(\boldsymbol{\%})\end{array}$ \\
\hline $1: 9$ & 500.1 & 52.10 & 104.18 \\
$1: 19$ & 1000.2 & 55.54 & 111.06 \\
$1: 39$ & 2000.4 & 54.72 & 109.42 \\
\hline
\end{tabular}

Table 9. Effect of dilution on tazobactam.

\begin{tabular}{cccc}
\hline $\begin{array}{c}\text { Dilution } \\
\text { factor }\end{array}$ & $\begin{array}{c}\text { Conc. } \\
(\boldsymbol{\mu} \mathbf{g} / \mathbf{m L})\end{array}$ & $\begin{array}{c}\text { Found Conc. Mean } \\
(\boldsymbol{\mu g} / \mathbf{m L})\end{array}$ & $\begin{array}{c}\text { Accuracy } \\
(\boldsymbol{\%})\end{array}$ \\
\hline $1: 9$ & 444.4 & 44.53 & 100.20 \\
$1: 19$ & 888.8 & 47.07 & 105.92 \\
$1: 39$ & 1777.6 & 46.31 & 104.21 \\
\hline
\end{tabular}

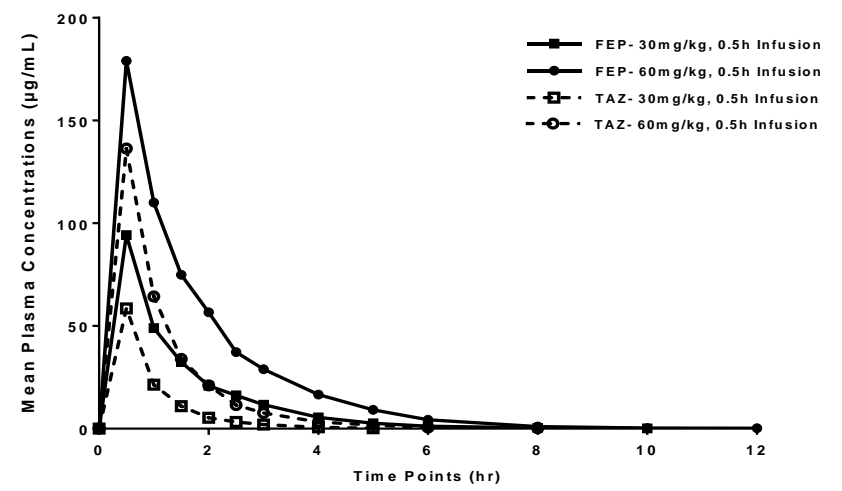

Figure 5. Mean plasma concentration vs time profile for cefepime and tazobactam at 30 and $60 \mathrm{mg} / \mathrm{kg}$, IV in beagle dogs.

Pharmacokinetic parameters were calculated by non-compartmental analysis using Phoenix Winnonlin 6.7 software. The Tmax was observed to be $0.5 \mathrm{~h}$ at the end of infusion. The mean Cmax 
at 30 and $60 \mathrm{mg} / \mathrm{kg}$ for cefepime were 94.25 and $179.0 \mu \mathrm{g} / \mathrm{mL}$ and for tazobactam were 58.52 and $136.40 \mu \mathrm{g} / \mathrm{mL}$. The mean $\mathrm{AUC}_{0-12}$ at 30 and 60 $\mathrm{mg} / \mathrm{kg}$ for cefepime were 123.4 and 280.4 $\mu \mathrm{g} . \mathrm{h} / \mathrm{mL}$ and for tazobactam were 49.8 and 140.5 $\mu \mathrm{g} . \mathrm{h} / \mathrm{mL}$. Overall dose proportionate linear increase in Cmax and AUC were observed for both drug components.

\section{Conclusion}

The described method for simultaneous estimation of cefepime and tazobactam in dog plasma is validated as per FDA and EMA guideline and found to be accurate, precise having required sensitivity. The method is economic due to fast and easy sample preparation as well as small run time. The method is successfully applied for pre-clinical dog PK studies.

\section{Financial and competing interest disclosure:}

The study is a part of $R \& D$ expenses of Wockhardt Limited. The authors have not financial or other affiliations with any other organization.

\section{Conflict of Interest:}

None to declare.

\section{Ethical conduct of research:}

The authors state that they have obtained appropriate approvals from local ethics committee for animal experimental investigations.

\section{References}

1. Yang Y, Rasmussen BA, Shlaes DM. Class A beta-lactamases enzyme-inhibitor interactions and resistance. Pharmacol Ther. 1999; 83(2):141-151.

2. Okamoto MP, Nakahiro RK, Chin A, Bedikian A, Gill MA. Cefepime: A new fourth-generation cephalosporin. Am J Hosp Pharm. 1994; 51(4):463-477.

3. Ródenas V, Parra A, Carcia-Villanova J, Gómez, MD. Simultaneous determination of cefepime and L-arginine in injections by second-derivative spectrophotometry. J Chromatogra B. 1995; 13(9):1095-1099.
4. Tseng SH, Yang YH, Chen YR, Chen SH. Determination of cefepime in plasma and cerebrospinal fluid by micellar electrokinetic chromatography with direct sample injection. Electrophoresis. 2004; 25(10-11):1641-1647.

5. Palacios FJ, Mochón MC, Sánchez JC, Carranza JH. Adsorptive stripping voltammetric determination of cefepime at the mercury electrode in human urine and cerebrospinal fluid and differential pulse polarographic determination in serum. $\mathbf{J}$ Pharm Sci. 2003; 92(9):1854-1859.

6. Valassis IN, Parissi-Poulou M, Macheras P. Quantitative determination of cefepime in plasma and vitreous fluid by highperformance liquid chromatography. J Chromatogr B Biomed Sci Appl. 1999; 721(2):249-255.

7. Chang YL, Chou MH, Lin MF, Chen CF, Tsai TH. Determination and pharmacokinetic study of unbound cefepime in rat bile by liquid chromatography with on-line microdialysis. J Chromatogr A. 2001; 914(12):77-82.

8. Palacios FJ, Callejón M, Sánchez JC, López MA, Pérez AG. Validation of an HPLC method for determination of cefepime (a fourth generation cephalosporin). Determination in human serum, cerebrospinal fluid and urine. Pharmacokinetic profiles. Chromatographia. 2005; 62(7):355-361.

9. Bu W, Sexton H, Fan X, Torres P, Houston P, Heyman I. The novel sensitive and high throughput determination of cefepime in mouse plasma by SCX-LC/MS/MS method following off-line micro elution 96-well solid-phase extraction to support systemic antibiotic programs. J Chromatogr B. 2010; 878(19):1623-1628.

10. Jagadeesh KV, Badarinadh P, Pavan KSR. Identification and characterization of new degradation products of cefepime dihydrochloride monohydrate drug substance during stress stability studies. Analytical Sciences. 2010; 26(10):1081-1086.

11. Fubara JO, Notari RE. Influence of $\mathrm{pH}$, temperature and buffers on cefepime degradation kinetics and stability predictions in aqueous solutions. J Pharm Sci. 1998; 87(12):1572-1576. 
12. Siddiqui M, Tariq A, Reddy K. High performance liquid chromatographic method for simultaneous determination of cefepime and sulbactam in pharmaceutical formulation (Supime) and biological samples. Int J Pharm. 2010; 6(3):271-277.

13. Elkhaïli H, Linger L, Monteil H, Jehl F. Highperformance liquid chromatographic assay for cefepime in serum. J of Chromatogr B. 1997; 690(1-2):181-18.

14. López KJV, Bertoluci DF, Vicente KM, Dell'Aquilla AM, Santos SRCJ. Simultaneous determination of cefepime, vancomycin and imipenem in human plasma of burn patients by high-performance liquid chromatography. J of Chromatogr B. 2007; 860(2):241-245.

15. M Ip, Au C, Cheung SW, Chan CY, Cheng AFB. A rapid high-performance liquid chromatographic assay for cefepime, cefpirome and meropenem. $\mathbf{J}$ Antimicrob Chemother. 1998; 42(1):121-123.

16. Breilh D, Lavallee C, Fratta A, Ducint D, Cony-Makhoul P, Saux MC. Determination of cefepime and cefpirome in human serum by high-performance liquid chromatography using an ultrafiltration for antibiotics serum extraction. J of Chromatogr B. 1999; 734(1):121-127.

17. Dave VM. Development and validation of RP-HPLC method for simultaneous estimation of cefepime hydrochloride and amikacin sulphate in injection dosage form. J Pharm Sci Biosci Res. 2012; 2(2):58-62.

18. Rao L, Krishna K, Kumar CK, Raja T. Simultaneous determination of piperacillin and tazobactum in bulk and pharmaceutical dosage forms by RP-HPLC. Int $J$ Pharm Pharm Sci. 2011; 3(2):134-136.

19. Augey V, Grosse PY, Albert G, Audran M, Bressolle F. High-performance liquid chromatographic determination of tazobactam and piperacillin in human plasma and urine. $\mathrm{J}$ Chromatogr B. 1996; 682(1):125-136.

20. Gandhimathi M, Saravanakuma M, Ravi TK. Validated ion pair HPLC method for simultaneous estimation of ceftriaxone sodium and tazobactum sodium in dosage form. Int J Pharma Bio Sci. 2010; 1(4):17-22.

21. Kumar RN, Rao GN, Naidu P. Stability indicating fast LC method for determination of ceftriaxone and tazobactam for injection related substances in bulk and pharmaceutical formulation. Int J Appl Biol Pharm. 2010; 1(1):145-157.

22. Guillaume Y, Peyrin E, Guinchard C. Rapid determination of sulbactam and tazobactam in human serum by high-performance liquid chromatography. J Chromatogr B. 1995; 665(2):363-371.

23. Pai PNS, Rao GK, Murthy MS, Prathibha H. Simultaneous estimation of piperacillin and tazobactam in injection formulations. Indian $\mathbf{J}$ Pharm Sci. 2006; 68(6):799-801.

24. Ocampo AP, Hoyt KD, Wadgaonkar N, Carver AH, Puglisi CV. Determination of tazobactam and piperacillin in human plasma, serum, bile and urine by gradient elution reversed-phase high-performance liquid chromatography. J Chromatogr $\quad$ B. 1989; 496(1):167-179.

25. Muratani T, Yokota E, Nakane T, Inoue E, Mitsuhashi S. In-vitro evaluation of the four beta-lactamase inhibitors: BRL42715, clavulanic acid, sulbactam and tazobactam. J Antimicrob Chemother. 1993; 32(3):421-429.

26. Guillaume Y, Peyrin E, Guinchard C. Rapid determination of sulbactam and tazobactam in human serum by high-performance liquid chromatography. J Chromatogr B Biomed Appl. 1995; 665(2):363-371.

27. Gianna DG, Michele F, Testore GP, Federici G, Pastore, A. High performance liquid chromatographic determination of plasma free and total tazobactam and piperacillin. $\mathbf{J}$ Chromatogr B. 2009; 877(1-2):86-88.

28. Xiang-Ming M, Zhi-Yun M, Liang Z, GuiFang D. Simultaneous determination of ceftazidime and tazobactam in injectable powder by reversed phase high performance liquid chromatography. J Chin Pharm Sci. 2004; 13(4):267-270.

29. Marselos SC, Archontaki HA. Development and optimization of a reversed-phase highperformance liquid chromatographic method for the determination of piperacillin and tazobactam in tazocin injectable powder. $\mathrm{J}$ Pharm Biomed Anal. 2002; 29(5): 787-793.

30. Navin KK, Rabindra KN, Raymond ML, Dipak AN. Development and validation of spectrophotometric methods for simultaneous estimation of Cefepime and Tazobactam in combined dosage form by area under curve 
and Q-Analysis. International Journal of Institutional Pharmacy and Life Sciences. 2012; 2(2):1-8.

31. Sunitha N, Sindhura L, Thangabalan B, Manohar BS. Development and Validation of RP-HPLC Method for Simultaneous Estimation of Cefepime and Tazobactam in Injection Formulation. Asian J. Pharm Ana. 2013; 3(4):131-137.

32. Neelima K, Rajendra PY, Appalraju N, Selina S, Nikhila R. Analytical Method Development and Validation of Cefepime Hydrochloride and Tazobactam Sodium in Bulk and Sterile Dry Powder for Injection by Gradient RP-HPLC. Indo American Journal of Pharmaceuticals Science. 2013; 3(10):8400-8407.

33. Bhavana M, Ramamohana RT, Sandhya M, Uma MRV. RP-HPLC Method Development and Validation for Simultaneous estimation of Cefepime and Tazobactam in Marketed formulation. International Journal of Pharmacy. 2013; 3(4):837-842.

34. Panchal VJ, Desai HT, Patel NB, Panchal KB. Development and Validation of Stability Indicating Method for Simultaneous Estimation of Cefepime and Tazobactam Injection using RP-UPLC Method. IOSR Journal of Pharmacy. 2014; 4(12):53-60.

35. FDA, Guidance for Industry Bioanalytical Method Validation., US Department of Health and Human Services, Food and Drug Administration, Centre for Drug Evaluation and Research (CDER). 2013.

36. European Medicines Agency., Guideline on bioanalytical method validation. 2012 . 